\title{
Politique
}

Politique

\section{Jean-Marc Piotte, La communauté perdue. Petite histoire des militantismes, Montréal, VLB Éditeur, 1987, 141 p.}

\section{Pierrette Bouchard}

Numéro 13, printemps 1988

Crise de décision

URI : https://id.erudit.org/iderudit/040592ar

DOI : https://doi.org/10.7202/040592ar

Aller au sommaire du numéro

Éditeur(s)

Société québécoise de science politique

ISSN

0711-608X (imprimé)

1918-6584 (numérique)

Découvrir la revue

Citer ce compte rendu

Bouchard, P. (1988). Compte rendu de [Jean-Marc Piotte, La communauté perdue. Petite histoire des militantismes, Montréal, VLB Éditeur, 1987, 141 p.] Politique, (13), 156-158. https://doi.org/10.7202/040592ar d'utilisation que vous pouvez consulter en ligne.

https://apropos.erudit.org/fr/usagers/politique-dutilisation/ 
Jean-Marc Piotte, La communauté perdue. Petite histoire des militantismes, Montréal, VLB Éditeur, 1987, 141 p.

Dès le premier paragraphe, Jean-Marc Piotte donne le ton du volume:

"Je voulais connaître comment les militants ont vécu la grande mouvance socioculturelle des deux dernières décennies, le bilan qu'ils en dressent, comment ils se situent dans la présente conjoncture... J'espérais ainsi mieux comprendre mon propre cheminement, découvrir comment me situer dans le présent, comment envisager l'avenir».

Et, effectivement, en lien avec les 26 entrevues qui soutiennent la trame de son volume, c'est le militant Piotte qui se découvre dans ce livre: son cheminement personnel depuis les années 1970, sa façon de concevoir cette recherche, ses réflexions politiques, ses émotions, son analyse et son honnêteté.

Tout en parlant de la militance, il nous parle de lui en tant que personne et cela m'a plu. Piotte réussit à faire sentir les motivations des militants et militantes à partir de sa propre im- 
plication. Il réussit à recréer le climat vécu par ceux et celles qui s'engageaient, le contexte socio-politique, les espoirs, les affrontements, les convictions profondes et surtout, l'ardeur qui soutenait l'adhésion.

Ce volume est un produit honnête en accord avec les valeurs que l'on sent partagées par les militants et militantes. Piotte ne cherche pas à imposer une recherche. Il se livre avec simplicité, sans jeter de la poudre aux yeux et sans que cela équivale à un manque de rigueur.

Le contenu du volume est basé sur des récits de vie. Nous y trouvons constamment reliés et confrontés les vécus personnel et politique des personnes. Cette façon d'appréhender la réalité, en plus de donner une couleur très particulière à la recherche, rend le lecteur ou la lectrice complice de l'auteur.

L'étude de la militance qui nous est présentée n'emprunte pas une approche sectorielle. Piotte y dresse le portrait d'idéologies, de groupes, de conflits de personnes.

Pourtant, autant j'ai aimé son type de recherche et sa façon de la présenter, autant je suis demeurée sceptique face à son cadre d'analyse. Il explique les motivations des militants et militantes à partir de leur intériorisation des trois vertus théologales: la foi, l'espérance et la charité. Bien que sa démonstration soit établie avec conviction et logique elle m'apparaît tellement simple qu'elle pourrait en devenir simpliste. Je suis convaincue que Piotte, contrairement à certains analystes de droite, n'a pas emprunté la voie de la facilité dans le cas de cette problématique, mais elle reste hasardeuse même si elle semble plausible. Les témoignages des militants et militantes sont utilisés de façon à confirmer son approche.

Je dois avouer que je préfere le ton intimiste du volume et je l'utiliserai aussi pour conclure que dans la vie militante il y a «quelque chose» dont Piotte rend compte: je crois qu'il ne s'agit 
pas vraiment de l'analyse ou du rationel dont il se sert mais plutôt du vécu, des questionnements et des déchirures dont il témoigne.

Pierrette Bouchard

Université Laval 